\title{
Crushed Puffed Rice-HPMC-Chitosan based Single-Unit Hydro- dynamically Balanced System for the Sustained Stomach Specific Delivery of Metoprolol Succinate
}

\author{
Shashank Soni ${ }^{1,2 *}$, Veerma Ram ${ }^{1}$, Anurag Verma ${ }^{2}$ \\ ${ }^{* 1,2}$ School of Pharmaceutical Sciences, Sardar Bhagwan Singh PG Institute of Biomedical Sciences and Research, Balawala, Dehradun, India. \\ ${ }^{2}$ School of Pharmaceutical Sciences, IFTM University, Moradabad, India.
}

\section{ARTICLE INFO}

Article history:

Received on: 04/10/2017

Accepted on: 27/11/2017

Available online: $30 / 12 / 2017$

\section{Key words:}

Biodegradable polymer, Crushed puffed rice, Hydrodynamically Balanced System, Metoprolol Succinate, Zero order kinetics model.

\begin{abstract}
Purpose: Developed and evaluated a Hydrodynamically Balanced System (HBS) capsule system using natural and novel biodegradable polymer used as Crushed Puffed Rice (CPR) alone and in combination with auxiliary polymers (High Molecular Weight Chitosan; HMWCH and Hydroxypropyl methylcellulose; HPMC K15) for stomach specific delivery.
\end{abstract}

Method: A total of nine formulations was prepared by manual shaking method and filled in colorless hard capsule shell size 1 . The prepared capsule was evaluated for parameters such as drug content, in vitro buoyancy and drug release in $0.1 \mathrm{M} \mathrm{HCl}$, drug delivery kinetics.

Results: Average floating time for the formulation is 08 hours. CPR is used as a buoyancy imparting agent due to its floating behavior; it floats in $0.1 \mathrm{M} \mathrm{HCl}(\mathrm{pH} \mathrm{1.2)}$ and remained unwetted for the time period of 05 hours. CPR, HPMC K15, and HMWCH have a significant effect $(p<0.05)$ on MS retarding. Formulation D1-D9 follows zero order model and Fickian diffusion which was confirmed by $\mathrm{R}^{2}$ value and Akaike Information Criteria (AIC).

Conclusion: The data obtained from the study suggests that CPR in combination with HMWCH or HPMC K15 or HPMC K15 + HMWCH has sufficient potential to be used as a carrier for stomach specific drug delivery.

\section{INTRODUCTION}

Metoprolol Succinate (MS) is a $\beta 1$-selective adrenergic blocking agent (Sandberg et al., 1998). Since the half-life of MS is $\sim 3$ to $4 \mathrm{~h}$ (Kendall et al., 1991), multiple doses are needed to maintain a constant plasma concentration for a good therapeutic response and improved patient compliance. It has also been

\footnotetext{
* Corresponding Author

Shashank Soni, School of Pharmaceutical Sciences. Sardar Bhagwan Singh PG Institute of Biomedical Sciences and Research, Balawala, Dehradun, India. Phone: +919410572306,

Email: shashank_soni64@yahoo.com
}

reported that MS absorption mainly takes place in the duodenum and jejunum and is directly proportional to the dose available (Jobin et al., 1985).

A gastroretentive is particularly useful for drugs that are primarily absorbed in the duodenum and upper jejunum segments (Narendra et al., 2006). MS is highly soluble throughout the physiological $\mathrm{pH}$. MS shows the several experimental properties like melting point $120{ }^{\circ} \mathrm{C}$, water solubility $1.699 \pm 004 \mathrm{mg} / \mathrm{L}$ (at 25 $\left.{ }^{\circ} \mathrm{C}\right), \log \mathrm{p} 1.88$, Caco2 permeability -4.59 , $\log \mathrm{S}-2.8$, pKa strongest acidic and basic 14.09 and 9.67 respectively, physiological charge 1 , hydrogen acceptor and donor count 4 and 2 respectively, polar surface area $50.72 \AA$, rotable bond count 09 , refractivity $76.7 \mathrm{~m}^{3} \mathrm{~mol}^{-1}$. 
It shows predicted ADMET properties like human intestinal absorption and $\mathrm{Caco} 2$ permeability positive behavior whereas negative effects on crossing blood-brain barrier (Blomqvist et al., 1988). It comes under the category of Biopharmaceutical Class System (BCS) I drug which states that it is extremely soluble and highly permeable. It is, therefore, a suitable candidate with the high solubility for an Hydrodynamically Balanced System (HBS) sustained delivery systems (Ravishankar et al., 2006; Wikstrand et al., 2003).

The present study involves the invention, development, and optimization of a novel gastroretentive floating, swellable, sustained release HBS capsules using CPR as a polymer for achieving gastroretention for MS by physical blending and filled in the hard gelatin capsule shell of size 01 . None of the work till date is reported by using CPR in drug delivery and gastroretention technology also by using MS. Chemically, CPR contains carbohydrates (as rice starch) as the major constituent (Kizil et al., 2002). Since these are very crispy in nature, they can be crushed with ball mill ease into fine low-density powder which is not easily wetted by water and can float over the surface of the water for a prolonged period of time (figure $10 \mathrm{D}$ ). This property of puffed rice motivated us to use it as buoyancy imparting agent and if possible as a release retarding polymer also. The current investigation is, therefore, envisaged to investigate the potential of CPR as a buoyancy imparter agent. This HBS gastroretentive capsule contains three polymers with different concentrations: High Molecular Weight Chitosan (HMWCH) - rapidly hydrating, rate controlling polymer, Hydroxypropyl methylcellulose K 15 (HPMC K15) - gel-forming agent, and Crushed Puffed Rice (CPR) - buoyancy importer and drug delivery carrier alone and in combination with auxiliary biodegradable and biocompatible polymers; HMWCH and HPMC K15. Nature of HMWCH is cationic and it is reported that it enhances the transport of drug via opening the tight junction of epithelial cells of the stomach (Sonaje et al., 2012). The positive charge, with very high charge density, present on the amino group surface of Chitosan binds to the negative charge of stomach mucosal lining, which results in the formation of hydrogel complex which retards the release of MS from the matrixes of Chitosan molecules and HPMC K15 is nonionic, when these come in contact with the dissolution media they form a gelatinous glassy structure at the outer surface. Now, this outer surface acts as an obstruction barrier for the media to penetrate inside the glassy structure and acts as a rate-limiting step for the release of the drug. The gel strength is also a rate-limiting step for the sustaining of drug (Soni et al., 2016). The gel strength can be increased by increasing the viscosity and this is achieved by the changing in the grades, addition with some another polymer or change in the concentration (Bernkop-Schnürch et al., 2012; Garg et al., 2008; Boldhane et al., 2010). Selection of HPMC and $\mathrm{HMWCH}$ is based on the previously reported work by one of the authors of this study (Soni et al., 2016; Verma et al., 2012; Verma et al., 2017). The pooled result of CPR alone and in combination with auxiliary polymers on the floating behavior and on in vitro release pattern of the MS has also been studied and reported in this present research novel experimental work.

\section{EXPERIMENTAL}

\section{Materials and Method}

Metoprolol Succinate (MS), High Molecular Weight Chitosan (HMWCH; Degree of Deacetylation > $85 \%$, apparent viscosity > $400 \mathrm{mPas}$ at $20{ }^{0} \mathrm{C}$, Brookfield), Dialysis membrane (1000 Dalton molecular weight) was procured from Merck (formerly Sigma-Aldrich; St. Louis), USA. Hydroxypropyl methylcellulose (HPMC K4M, apparent viscosity 3000-5600 cps at $20{ }^{\circ} \mathrm{C}$ and $\mathrm{K} 15 \mathrm{M}$, apparent viscosity $11250-21000 \mathrm{cps}$ at $20{ }^{\circ} \mathrm{C}$ ) obtained as a gift sample from Colorcon Asia Private Limited, India. Oryza Sativa (crushed puffed rice) obtained from the local market of Dehradun, India. $0.45 \mu \mathrm{m}$ membrane filter was procured from Rankem, India. Double distilled water was used throughout the experiment. All other chemicals and reagents used were of analytical grade.

\section{Development of CPR powder}

CPR was dried in the tray dryer at a temperature of $45{ }^{\circ} \mathrm{C}$ to remove the moisture from its pore till the equilibrium moisture content (EMC) was achieved followed by transfer in the ball mill for size reduction. After running time of 10 minutes the crushed CPR was collected over butter paper and passed over a sieve \# 120 to get a monodisperse powder, undersize particles were collected and stored in an airtight glass vial to prevent the entry of moisture.

\section{Preparation of Single-unit Hydrodynamically Balanced System (HBS) Capsules containing formulations by ordered mixing}

Optimized formulations (Table 1) of HBS capsules were prepared to ordered mixing technique by placing the drug between layers of polymers in a glass vial $(10 \mathrm{ml})$ and shaken vigorously manually by hand for $5 \mathrm{~min}$., followed by encapsulation in colorless hard gelatin capsule shell (size 1) using laboratory capsule filling machine. The manual shaking procedure had advantages that it did not cause size reduction of neither drug nor polymer during mixing that would believe to affect the release profile of formulations during drug release studies (Soni et al., 2016).

Table 1: Formulation composition of MS with HPMC, HMWCH and CPR

\begin{tabular}{ccccc}
\hline $\begin{array}{c}\text { Formulation } \\
\text { Code }\end{array}$ & $\begin{array}{c}\text { MS } \\
(\mathbf{m g})\end{array}$ & $\begin{array}{c}\text { CPR* } \\
\text { (sieve\#120) }(\mathbf{m g})\end{array}$ & $\begin{array}{c}\text { HMWCH* } \\
(\mathbf{m g})\end{array}$ & $\begin{array}{c}\text { HPMC } \\
\text { K15* (mg) }\end{array}$ \\
\hline D1 & 25 & 75 & --- & --- \\
D2 & 25 & 75 & 75 & --- \\
D3 & 25 & 75 & --- & 75 \\
D4 & 25 & 75 & 37.5 & 37.5 \\
D5 & 25 & --- & 75 & --- \\
D6 & 25 & -- & --- & 75 \\
D7 & 50 & 75 & 75 & --- \\
D8 & 50 & 75 & --- & 75 \\
D9 & 50 & 75 & 37.5 & 37.5 \\
\hline
\end{tabular}

MS: Metoprolol Succinate, CPR: Crushed Puffed Rice, HMWCH: High Molecular Weight Chitosan, HPMC: Hydroxypropyl Methylcellulose (Hypromellose). *Concentration of all the polymers were chosen on the basis of initial trials study conducted for efficient buoyancy. 


\section{Thermal characterization of CPR}

Thermal characterization was performed on EXSTAR TG/DTA 6300 and it includes Thermo Gravimetric Analysis (TGA), Differential Thermal Analysis (DTA) and Derivative Thermo Gravimetric Analysis (DTG), having the sensitivity of 0.2 $\mu \mathrm{g}$ for TGA and $0.06 \mu \mathrm{V}$ for DTA. It was carried out to study the determination of characteristic peaks (endothermic and exothermic) and heat of melting was recorded of a drug, excipient and drug-excipient mixtures in the present investigation. The study was carried out at $5{ }^{\circ} \mathrm{C} / \mathrm{min}$ till melting point in the presence of inert nitrogen (N2) using a duplicate sample of $5 \mathrm{mg}$ in the crimped aluminum pan. The flow rate of purge gas is $2 \mathrm{ml} /$ minute (Soni et al., 2016).

\section{Functional group characterization of CPR by using Fourier Transform Infrared spectroscopy (FTIR) studies}

Fourier Transform Infrared spectroscopy (FTIR) was performed by BX2, Perkin Elmer; Norwalk, USA. The FTIR analysis was carried out to confirm the presence of the functional group in the compound. The method involved is of direct compression technique by using potassium bromide $(\mathrm{KBr})$. The $\mathrm{KBr}$ pellet of approximately $1 \mathrm{~mm}$ diameter of the drug was prepared grinding 3-5 mg of sample with 100-150 $\mathrm{mg}$ of $\mathrm{KBr}$ in pressure compression machine. The sample pellet was mounted in FTIR compartment and taken the scan at wavelength $4000 \mathrm{~cm}^{-1}$ $400 \mathrm{~cm}^{-1}$.

All optical measurements were performed at room temperature under ambient conditions (Soni et al., 2016).

\section{Stability studies of MS in $0.1 \mathrm{M} \mathrm{HCl}(\mathrm{pH}$ 1.2)}

Stability studies of MS were performed in $0.1 \mathrm{M} \mathrm{HCl}(\mathrm{pH}$ 1.2) were determined in order to assure that whether the drug will remain stable throughout the period of drug release in acidic $\mathrm{pH}$. In this $2 \mathrm{mg} / \mathrm{ml}, 3 \mathrm{mg} / \mathrm{ml}$ and $4 \mathrm{mg} / \mathrm{ml}$ solution of MS is prepared in $0.1 \mathrm{M} \mathrm{HCl}(\mathrm{pH} \mathrm{1.2)}$. The temperature of the system is maintained at $37 \pm 0.5{ }^{\circ} \mathrm{C}$. One $\mathrm{ml}$ of the sample was withdrawn periodically with the help of a syringe and at the mouth $0.45 \mu \mathrm{m}$ filter membrane was placed, replaced by freshly prepared $0.1 \mathrm{M}$ $\mathrm{HCl}(\mathrm{pH}$ 1.2). The samples are suitably diluted by the same followed by sonication for 5 minutes and were measured at $224 \mathrm{~nm}$ (Shimadzu UV-1800) (Soni et al., 2016; Verma et al., 2012).

\section{Determination of drug content in formulations}

The drug concentration in each formulation was determined in triplicate by emptying each capsule containing formulation in $0.1 \mathrm{M} \mathrm{HCl}$ at $37 \pm 0.5{ }^{\circ} \mathrm{C}$. This mixture is stirred for 2 hours at $200 \mathrm{rpm}$ and analyzed at $224 \mathrm{~nm}$ using UV-Vis spectrophotometer (Soni et al., 2016; Verma et al., 2012).

\section{Effect of $\mathrm{pH}$ and temperature on swelling behavior of CPR and determination of swelling kinetics}

In order to study the swelling behavior of CPR (approximately $1.00 \mathrm{~g}$ ) were dispersed in the different solvent: $\mathrm{pH}$
1.2 buffer solution $(0.1 \mathrm{M} \mathrm{HCl})$, and $\mathrm{pH} 6.8$ buffer solution (phosphate buffer). The CPR was placed in the swelling solution using dialysis membrane (M.W:1000 Dalton) and the weights of the swollen samples were measured against time after the excess surface water over the dialysis membrane was removed with a help of dry piece of filter paper (Martinez-Ruvalcaba et al., 2009). The swelling ratio $(\mathrm{Q})$ for each sample at the specified time was calculated. Temperature also plays an important role in swelling behavior of polymers. In this work investigation of the swelling behavior of CPR at in vitro body temperature $\left(37 \pm 0.5{ }^{\circ} \mathrm{C}\right)$ and at extreme temperature $50 \pm 0.5{ }^{\circ} \mathrm{C}$ was performed using dialysis membrane (M.W:1000 Dalton) as per the procedure described by Gupta et al., 2012. The weighed amount of CPR was placed in a dialysis bag (M.W:1000 Dalton) in pH 1.2 buffer solution (0.1 M $\mathrm{HCl}$ ) by keeping temperature $37 \pm 0.5{ }^{\circ} \mathrm{C}$ and $50 \pm 0.5{ }^{\circ} \mathrm{C}$ using dissolution apparatus USP XXIV type II (paddle) apparatus (Electrolab; TDT-08L, Mumbai; India). The weights of the swollen samples were measured against time after the excess surface water over the dialysis membrane was removed with a help of filter paper.

The swelling ratio (Q) at different time interval and swelling rate kinetics $(\mathrm{K})$ was for each concentration of $\mathrm{CPR}$ at different $\mathrm{pH}$ was calculated and reported.

\section{Water Holding Capacity (WHC) determination for formulations}

WHC was defined as the ratio (\%) of gel weight after centrifugation to the original gel weight and was determined in triplicate. It was determined by the method reported by (Huang $e t$ al., 2003; Verma et al., 2012) by making some slight modifications. Individual formulations were kept in a dialysis membrane (1000 Dalton molecular weight) by holding both the sides tied with the help of thread. These formulations containing dialysis bags were transferred into the dissolution vessels containing $900 \mathrm{ml} 0.1 \mathrm{M} \mathrm{HCl}(\mathrm{pH} 1.2)$ maintaining temperature 37 $\pm 0.5{ }^{\circ} \mathrm{C}$ (Electrolab; TDT-08L, Mumbai; India). At specified intervals of time formulations from the dialysis bag transferred out in a graduated centrifuge tube for centrifugation at room temperature at $10000 \mathrm{rpm}$ for 10 minutes. These contents were removed out from the tube weight taken and compared with the initial weight and again transferred into the dialysis bags for the procedure.

\section{In vitro buoyancy studies}

The HBS capsules were placed in $900 \mathrm{ml}$ of in simulated gastric fluid, pH 1.2 in USP XXIV type II apparatus (Electrolab; TDT-08L, Mumbai; India) at $50 \mathrm{rpm}$ maintained at $37 \pm 0.5^{\circ} \mathrm{C}$. The time during which the formulations remained buoyant was observed and was taken as the floating time (Soni et al., 2016; Verma et al., 2012).

\section{In vitro release studies and drug delivery kinetics}

All the prepared ordered mixed HBS capsules were immersed in $900 \mathrm{ml}$ of $0.1 \mathrm{M} \mathrm{HCl}$ using USP XXIV type II 
(paddle type) apparatus (Electrolab; TDT-08L, Mumbai; India) at $50 \mathrm{rpm}$ having temperature $37 \pm 0.5^{\circ} \mathrm{C}$. Aliquots of $1 \mathrm{ml}$ as samples were withdrawn with the help of syringe fitted with $0.45 \mu \mathrm{m}$ membrane filter for analysis and an equal amount of fresh $0.1 \mathrm{M}$ $\mathrm{HCl}$ was replaced in the dissolution vessel to maintain the sink condition (Soni et al., 2016). Obtained samples were analyzed for their absorbance at $224 \mathrm{~nm}$ and the concentration was determined by the standard curve of MS.

In order to explain the drug release from the formulation, various equations are used like Zero Order, First Order, Higuchi model, and Korsmeyer-Peppas equation was used. The dosage form which follows zero order kinetics follows to a uniform rate of drug release from the solid dosage form. The dosage form which follows zero order kinetics provides maximum therapeutic value with minimum side effects. First order release relates the initial amount release rapidly followed by decrease/sustaining the release of drug from the polymeric reservoir. Such type of systems in plasma not maintains the plasma drug concentration profile uniformity. Higuchi mechanism relates the drug release from the matrix system by the diffusion mechanism which is given by

$$
\mathrm{Q}=\mathrm{K} \sqrt{ } \mathrm{t} \ldots \text { (1) }
$$

Where $\mathrm{Q}$ is the accumulative amount of drug release from the polymeric matrixes after coming to the dissolution medium in time $\mathrm{t}$ and $\mathrm{K}$ denominates the release constant. Apart from this Korsmeyer-Peppas equation was also applied to investigate mechanism which takes place from the swollen polymeric matrices which are given by

$$
\mathrm{Mt} / \mathrm{M} \infty=\mathrm{Kt}_{\mathrm{n}} \ldots \text { (2) }
$$

Where $\mathrm{Mt} / \mathrm{M} \infty$ is the fraction of drug released in time $\mathrm{t}$ and $\mathrm{K}$ is the structural and geometrical constant, and $\mathrm{n}$, is the release exponent. If $\mathrm{n}=0.5$ it follows Fickian diffusion mechanism, if it $0.5<\mathrm{n}<1.0$, the release follows Non Fickian diffusion and diffusion mechanism if $n=1.0$ and more than 1.0 it follows super case II transport (zero order). Korsmeyer Peppas equation explains the mechanism of drug release by the dual effect of diffusion and relaxation of polymeric strands after coming to the dissolution medium. Apart from $\mathrm{r} 2$ value, Akaike Information Criteria (AIC) was also used to validate the release kinetics value. AIC value was calculated by KinetDS-3.0 software.

$$
\mathrm{AIC}=\mathrm{n} * \mathrm{In}(\mathrm{WSSR})+2 * \mathrm{p} \ldots
$$

Where $\mathrm{n}$ is the number of dissolution points, $\mathrm{p}$ is the number of parameters of the exemplary to be calculated and WSSR is the weighed sum square residues. When compared with the several models from a given set of data, the model which has the smallest AIC value is regarded as a best-fit model. All the models are applied to the first $60 \%$ of drug release from the controlled release polymeric matrices (Soni et al., 2016; Soni et al., 2017; Verma et al., 2012).

\section{Statistical analysis}

All the data were analyzed by Students t test to determine statistical differences between the results. A probability value $p<$ 0.05 was considered statistically significant. Statistical analysis of obtaining the data was performed by using Graphpad Instat ${ }^{\circledR}$ software.

\section{RESULTS AND DISCUSSION}

\section{Thermal Characterization of CPR}

Figure 1 represents the thermal behavior of CPR under experimental condition. DTA shows the narrow endothermic peak at $288{ }^{0} \mathrm{C}$ (enthalpy $25.9 \mathrm{~mJ} / \mathrm{mg}$ ) which represents the glass transition temperature of biopolymer used. The exothermic peak at $499{ }^{0} \mathrm{C}$ (enthalpy $-921 \mathrm{~mJ} / \mathrm{mg}$ ) and $636{ }^{0} \mathrm{C}$ (enthalpy $-1.05 \mathrm{~J} / \mathrm{mg}$ ) represents the slow degradation of biopolymer. DTG and TG thermogram represent the biopolymer are stable up to the temperature of $290{ }^{0} \mathrm{C}$, exothermic peak at $633{ }^{\circ} \mathrm{C}$ represents the degradation of biopolymer and maximum loss of mass $41.6 \%$ occurs from temperature $253{ }^{\circ} \mathrm{C}$ to $316{ }^{\circ} \mathrm{C}$ and $4.7 \%$ loss of mass occurs at temperature $639{ }^{\circ} \mathrm{C}$.

Functional group characterization of CPR by using Fourier Transform Infrared spectroscopy (FTIR) studies

Figure 2 shows the FTIR spectra of CPR. The peak at $3403.46 \mathrm{~cm}^{-1}$ corresponds to the alcohol $(\mathrm{O}-\mathrm{H})$ stretching having strong and broad absorption intensity. Sharp and broad peak intensity at $2927.16 \mathrm{~cm}^{-1}$ corresponds to the $\mathrm{CH}_{2}$ deformation having medium absorption intensity. Broad and sharp peak intensity at $1649.58 \mathrm{~cm}^{-1}$ corresponds to the alkene $(\mathrm{C}=\mathrm{C})$ having medium peak intensity which represents the tightly bound water adsorbed in the region of starch (Santha et al., 1990; Wilson et al., 1991). The peak intensity at $1412.57 \mathrm{~cm}^{-1}$ represents the C-O-O stretch, $\mathrm{CH} 2$ bending. Peak intensity at $1380.21 \mathrm{~cm}^{-1}$ represents the $\mathrm{C}-\mathrm{O}-\mathrm{H}$ bending, $\mathrm{CH}_{2}$-twisting. Small peak intensity at $1241.86 \mathrm{~cm}$ ${ }^{1}$ represents the $\mathrm{CH}_{2} \mathrm{OH}$ (side chain) related mode. Broad, sharp peak intensity at $1156.98 \mathrm{~cm}-1$ represents C-O, C-C stretching mode, whereas, the peak intensity at $1085.85 \mathrm{~cm}^{-1}$ represents $\mathrm{C}-\mathrm{O}$ $\mathrm{H}$ bending and the peak intensity at $1022.02 \mathrm{~cm}^{-1}$ and $931.48 \mathrm{~cm}^{-1}$ represents anhydro-glucose ring at $\mathrm{O}-\mathrm{C}$ stretching. A FTIR spectrum below $800 \mathrm{~cm}^{-1}$ represents complex vibrational modes due to the skeletal mode vibrations of the pyranose ring in the glucose ring (Kizil et al., 2002; Huang et al., 2007). All these peaks are present in the parent peaks of starch as investigated by authors (Kizil et al., 2002; Huang et al., 2007; Santha et al., 1990); since we are using CPR as a novel biodegradable polymer for drug delivery technology this puffed rice also contains starch as its main constituent. From this FTIR we can say that the basic constituent present in CPR is starch on the preliminary basis which is used as buoyancy imparting agent. 


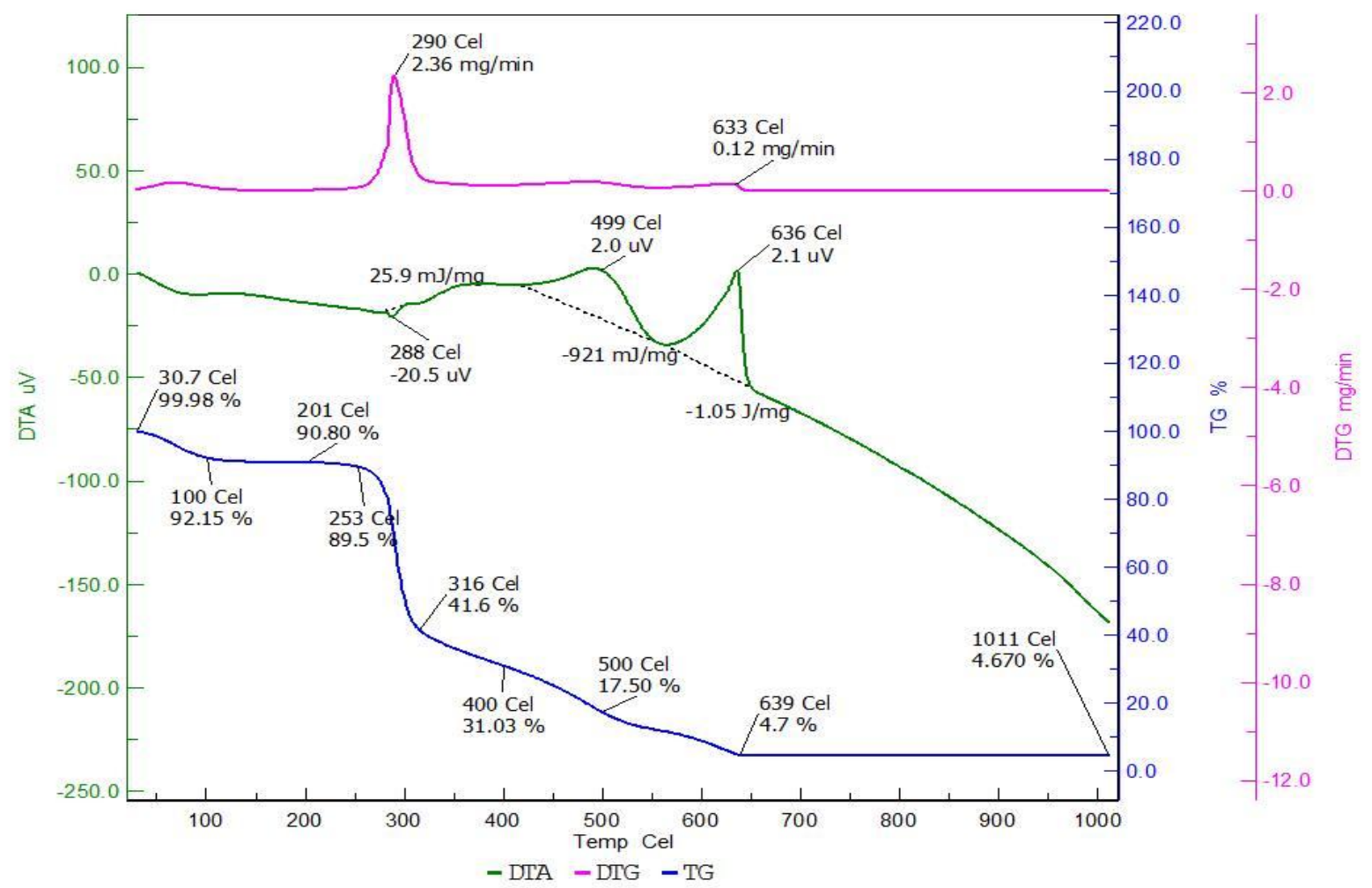

Fig. 1: Thermal characterization of CPR

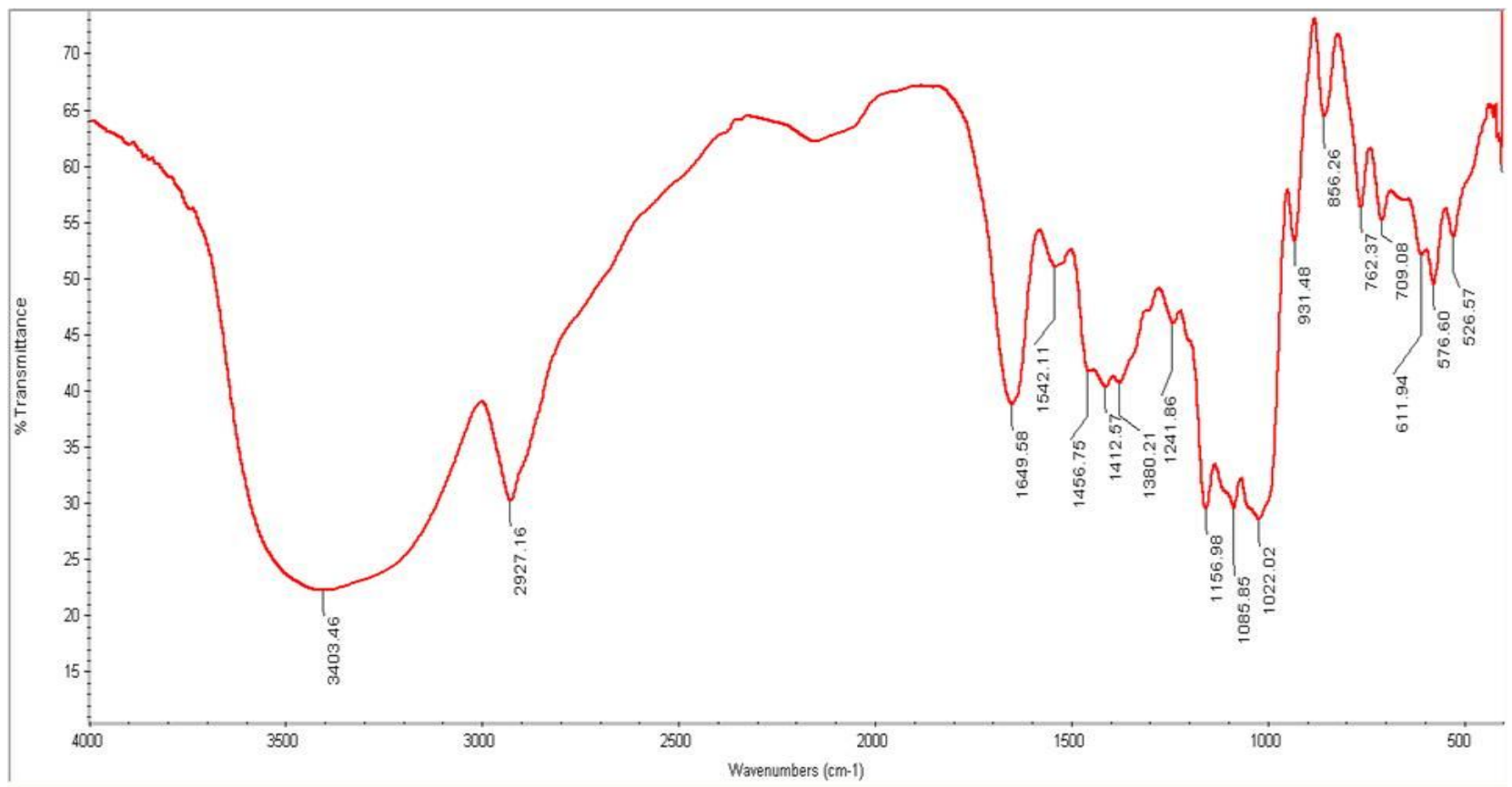

Fig. 2: FTIR spectra of CPR under wavelength of $4000 \mathrm{~cm}^{-1}-400 \mathrm{~cm}^{-1}$ 


\section{Stability studies of MS in 0.1 M HCl (pH 1.2)}

MS shows some degradation in $0.1 \mathrm{M} \mathrm{HCl}$ (pH 1.2) in the concentration range of $2 \mathrm{mg} / \mathrm{ml}, 3 \mathrm{mg} / \mathrm{ml}$ and $4 \mathrm{mg} / \mathrm{ml}$ but the degradation was not significantly found (figure 3$)(p>0.05)$. The debasement of the drug was not seen concentration dependent.

The debasement of the drug was not observed during drug release studies due to the formation of glassy polymeric structure in the dissolution media due to the nature of hydrophilic colloid it directly prevents the drug from the degradation. This assures the drug will be stable throughout the period of drug release in $0.1 \mathrm{M} \mathrm{HCl}(\mathrm{pH} 1.2)$.

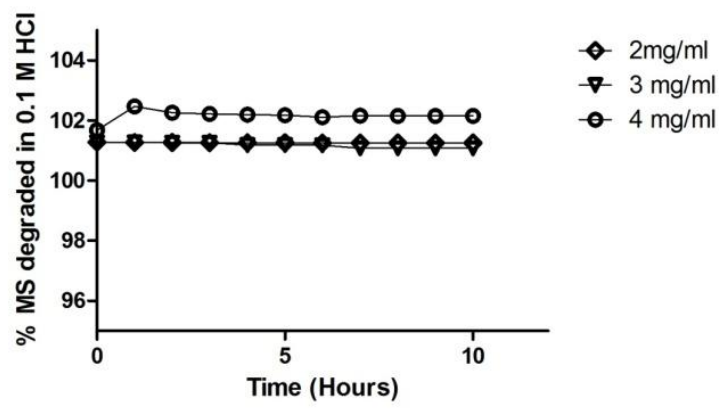

Fig. 3: $\%$ MS degradation in $0.1 \mathrm{M} \mathrm{HCl}(\mathrm{pH} 1.2)(\mathrm{n}=3$, mean \pm S.D)

\section{Effect of pH and temperature on swelling behavior of CPR}

During design and development of oral delivery of a drug (s), the formulator must consider the nature of $\mathrm{pH}$ throughout the gastrointestinal tract. It varies from acidic in the stomach to slightly alkaline in the intestine. The structure of the polymers with large numbers of pores connected to one another to form capillary channels is favorable for the easy diffusion of the swelling medium into the polymeric matrix and thus the rate limiting step for swelling of the polymers.

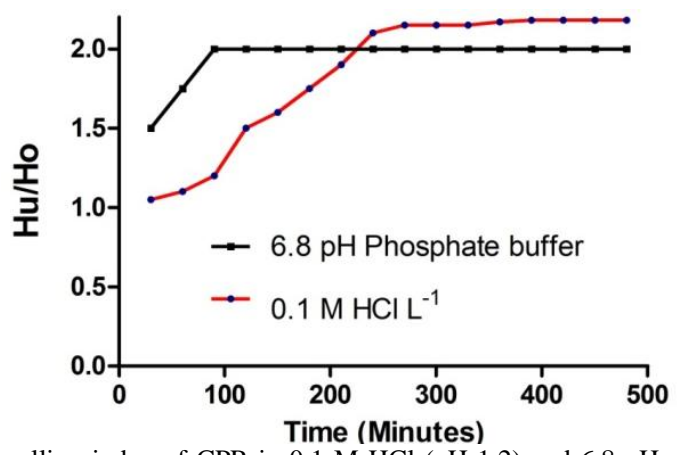

Fig. 4: Swelling index of $\mathrm{CPR}$ in $0.1 \mathrm{M} \mathrm{HCl}(\mathrm{pH} 1.2)$ and $6.8 \mathrm{pH}$ phosphate buffer $(n=3$, mean \pm S.D)

Swelling of CPR in the $\mathrm{pH} 1.2$ was significant good. Since CPR composed of carbohydrate group which can dissociate or get protonated at $\mathrm{pH} 1.2$ of the swelling media, the degree of swelling of CPR underwent appreciable change (figure 4). At $\mathrm{pH}$ 1.2 slight swelling capacity of the CPR was observed due to the protonation of carbohydrate groups. The degree of ionization also caused an increase in ion osmotic pressure. Capillary wetting of interconnected open pores of CPR also responsible for a higher degree of swelling in the medium. When the $\mathrm{pH}$ reached 6.8 , all the carbohydrate groups were converted to the salt form and the maximum swelling was obtained which accounted for similar swelling behaviors at alkaline $\mathrm{pH}$. Swelling behavior of the CPR at different temperatures and $\mathrm{pH} 1.2$ (in vivo body temperature; 37 $\pm 0.5{ }^{0} \mathrm{C}$ and $50 \pm 0.5{ }^{0} \mathrm{C}$ ) using dissolution apparatus was performed. As the temperature reaches to $37 \pm 0.5{ }^{\circ} \mathrm{C}$, the $\mathrm{CPR}$ swelled faster, and the equilibrium swelling ratio was enhanced accordingly. This was due to the disentanglement of interpenetrated swellable polymeric chains and destruction of hydrogen bonding between polymer molecules. At a higher temperature, the chain mobility was increased which helped the network expansion (Zhang et al., 2005). Such temperature responsiveness was also attributed to the high porosity of the CPR as the more pores would enhance the uptake of water during swelling in comparison with less porous hydrogels (figure 5).

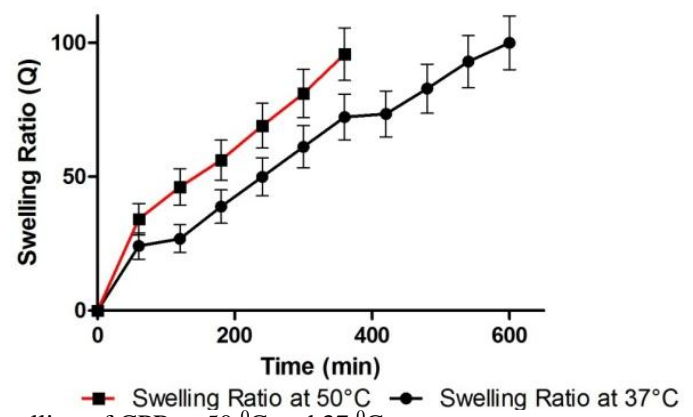

Fig. 5: Swelling of CPR at $50{ }^{\circ} \mathrm{C}$ and $37{ }^{\circ} \mathrm{C}$

\section{Effect of change in pH on CPR Swelling Kinetics}

Lee et al., 1999 reported that the swelling of the polymer is described by the second order kinetics. For most of the pharmaceutical formulation for drug delivery and controlling the release of medicaments from the matrixes swelling of the polymer is the rate determining step (Lee et al., 1999). This second order kinetics is indicated by an equation

$\mathrm{dH} / \mathrm{dt}=\mathrm{k}(\mathrm{Hu}-\mathrm{H})^{2} \ldots$ (4)

Where, $\mathrm{k}$ is swelling rate constant

By integrating the above second order equation, we get equation 5 and 6 ,

$\mathrm{t} / \mathrm{H}=1 / \mathrm{k}_{\infty}+\mathrm{t} / \mathrm{H}_{\infty} \ldots(\mathbf{5})$

$\mathrm{k}_{\infty}=\mathrm{kH}^{2} \ldots(\mathbf{6})$

Where, $k_{\infty}$ is the equilibrium swelling rate constant (table 2 and figure 6). When the swelling kinetics corresponds to a second order kinetics, Equation (4) is a linear relationship, and $H_{\infty}$ and $k$ corresponds to the slope and intercept of the line (Katime et al., 2004; Hanafi et al., 2000).

Table 2: Swelling rate constant $(k)$

\begin{tabular}{ccc}
\hline $\begin{array}{c}\text { Concentration } \\
\text { of CPR }(\% \\
\text { weight) }\end{array}$ & $\mathbf{0 . 1} \mathbf{~ M ~ H C l ~ ( p H ~ 1 . 2 ) ~}$ & $\mathbf{6 . 8} \mathbf{~ p H}$ phosphate buffer \\
\hline 0.5 & 0.030 & 0.039 \\
5 & 0.045 & 0.050 \\
10 & 0.085 & 0.098 \\
15 & 0.120 & 0.134 \\
20 & 0.190 & 0.234 \\
\hline
\end{tabular}




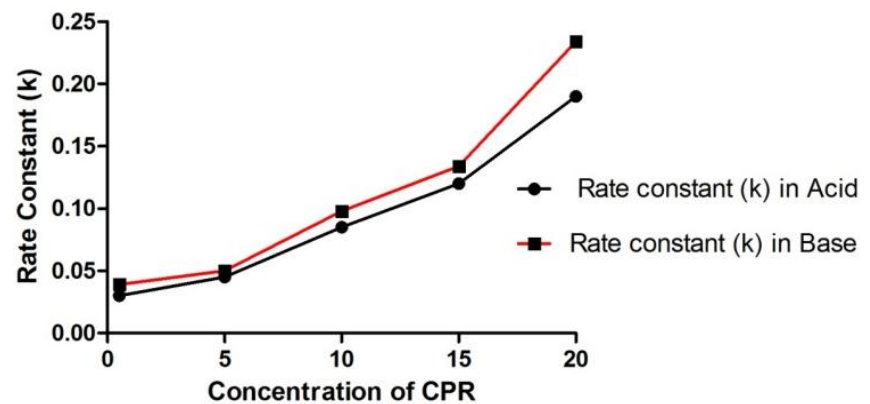

Fig. 6: Swelling rate constant (k) in acid; $\mathrm{pH} 1.2$ and base; $\mathrm{pH} 6.8(\mathrm{n}=3$, mean \pm S.D)

Taking into the consideration that the swelling process is affected by specific relations between the molecules of the swelling medium and the polymer pendant groups' one can expect many kinds of polymer-swelling medium interactions, and probably a complex kinetics. The decrease in the swelling rate when the CPR concentration increases ( $\mathrm{k}$ increases) suggests that specific interactions between the polymeric network loaded with CPR and the medium are weaker when compared to the interactions that occur with the polymeric network without CPR.

\section{Water Holding Capacity (WHC) determination for formulations}

Change in \% WHC was used to illustrate the interaction potential of MS with CPR and along with the others auxiliary polymers like HMWCH and HPMC K15. CPR is dispersible in warm water $\left(37{ }^{0} \mathrm{C}\right)$ to form viscous system alone and it's viscosity forming tendency increases when added with MS, $\mathrm{HMWCH}$, and HPMC K15. MS when combines with CPR it forms the gel network type structure but its \% WHC was not determined due to disruption of the structure after centrifugation. For efficient WHC, swelling of the polymer is the very rate-limiting step. $\mathrm{HMWCH}$ contains $-\mathrm{NH}_{2}-$ groups bound by polymer chains. In the presence of acidic gelation medium, the polymer chains in $\mathrm{HMWCH}$ absorb dissolution medium and the binding of $\mathrm{H}^{+}$causes the polymer to swell $\left(\mathrm{NH}^{+}\right)$. It was noted that the HBS capsule formulations prepared with MS and HMWCH, HPMC K15 and CPR alone have a different WHC profile (table 3 and figure 7). The poor \% WHC could be attributed to the weak gel network formed due to the presence of highly soluble MS $\left(192 \mathrm{mg} / \mathrm{ml}\right.$ in $0.1 \mathrm{M} \mathrm{HCl}$ at $\left.37{ }^{0} \mathrm{C}\right)$. Thus, to increase the $\%$ WHC, the auxiliary polymers (HPMC K15 and $\mathrm{HMWCH}$ ) were incorporated into HBS capsule formulations. These auxiliary polymers are expected to counter the rapid disruption of the gel layer, thereby preserving the unity of the swollen hydrogel.

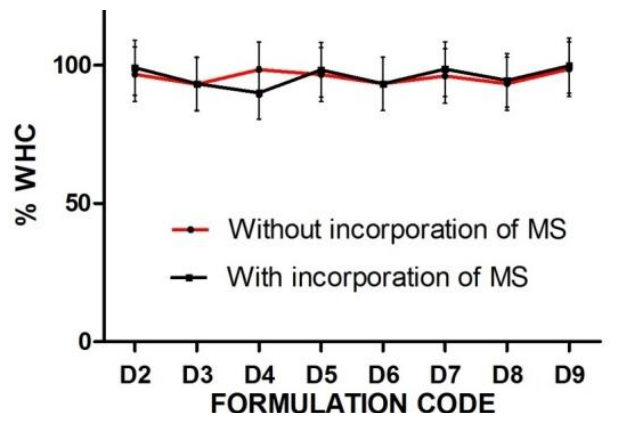

Fig. 7: WHC of formulations D1 - D9 $(n=3$, mean \pm S.D)

All the formulations exhibited a better water holding capacity when MS was incorporated. It was noted that after the addition of auxiliary polymer $\%$ WHC increases. The addition of auxiliary polymer(s) resulted in improvement in swelling of the CPR which resulted in the increase in bulk volume. Without the incorporation of MS the \% WHC decreases. This reason is attributed due to the MS being hydrophilic in nature, swelling of MS in acidic gelation medium will be a more entropy-favored process and as the number of ions within the hydrogel structure increases, more and more osmotic and electrostatic forces will be created within the hydrogel structure (Verma et al., 2017). This leads to increased dissolution medium $(0.1 \mathrm{M} \mathrm{HCl})$ uptake and forces a typical hydrogel to behave thermodynamically like a liquid as it occupies more space. Moreover, MS being highly hydrophilic, this further dilutes the effectiveness of the aqueous gel layer due to high diffusion driving force and consequently increased erosion. As a result, this hydrogel lost its integrity and became distorted, leading to burst after centrifugation.

This above all the findings reveals that the all the formulations (D1-D9) remained buoyant during the drug release studies. This parameters are the rate limiting steps for the achieving the gastroretention.

Table 3: WHC determination of formulations D1-D9.

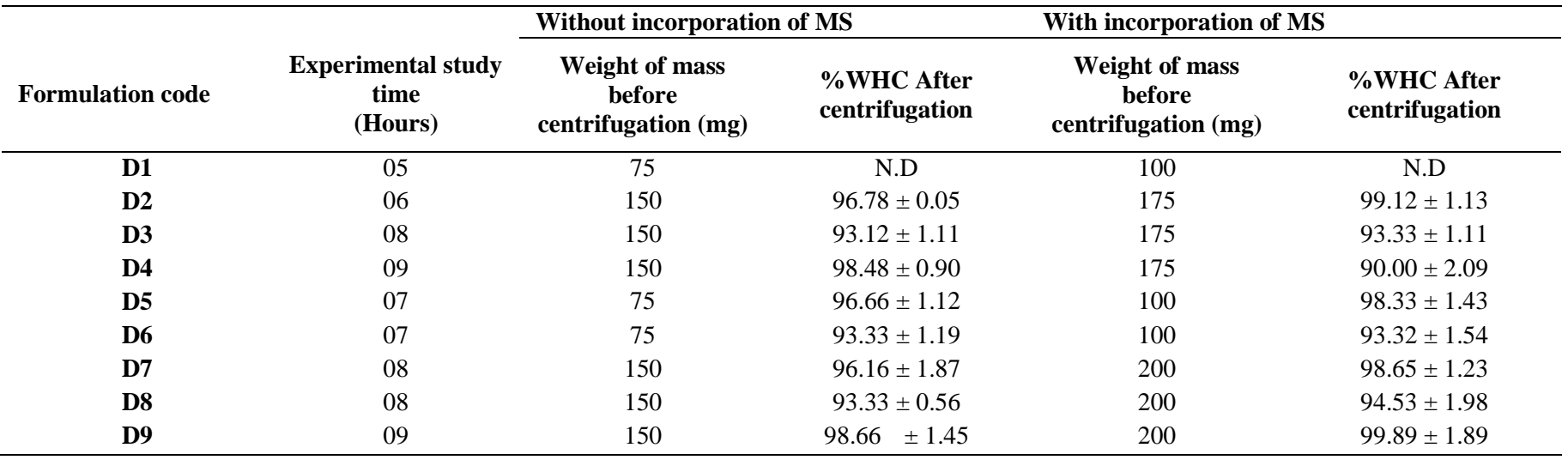


Table 4: Lag time, in vitro buoyancy studies and \% Drug concentration determination

\begin{tabular}{|c|c|c|c|c|}
\hline $\begin{array}{l}\text { Formulation } \\
\text { code }\end{array}$ & $\begin{array}{l}\text { Floating lag } \\
\text { time } \\
\text { (Seconds) }\end{array}$ & $\begin{array}{l}\text { Buoyancy time } \\
\text { (Hours) }\end{array}$ & $\begin{array}{l}\text { \% Drug } \\
\text { concentration } \\
\text { uniformity* }\end{array}$ & Comments \\
\hline D1 & Nil & Buoyant for 05 hours & $95.56 \pm 1.10$ & $\begin{array}{l}\text { Remained buoyant for } 05 \mathrm{hr} \text { as a regular polymeric raft after the } \\
\text { disruption of capsule shell. Initially remained unwetted throughout the } \\
\text { period of buoyancy. Drug release was found to be erratic. }\end{array}$ \\
\hline D2 & Nil & Buoyant for 06 hours & $97.89 \pm 1.56$ & $\begin{array}{l}\text { Remained buoyant for } 06 \mathrm{hr} \text {. Acquired the shape of a cylindrical mass } \\
\text { after the disruption of capsule shell }(\mathrm{t}=0.5 \text { hours }) \text {. Drug release was } \\
\text { retarded up to } 06 \mathrm{hr} \text {. }\end{array}$ \\
\hline D3 & Nil & Buoyant for 08 hours & $95.45 \pm 1.62$ & $\begin{array}{l}\text { Formulation sank after } 08 \mathrm{hr} \text {. Acquired the shape of irregular gel matrix. } \\
\text { Drug release was retarded up to } 08 \mathrm{hr} \text { but irregular. }\end{array}$ \\
\hline D4 & Nil & Buoyant for 09 hours & $98.10 \pm 1.11$ & $\begin{array}{l}\text { Formulation sank after } 09 \mathrm{hr} \text {. Acquired the shape of cylindrical gel matrix. } \\
\text { Drug release was retarded up to } 08 \mathrm{hr} \text { and release pattern was found to be } \\
\text { smooth. }\end{array}$ \\
\hline D5 & Nil & Buoyant for 07 hours & $96.48 \pm 1.34$ & $\begin{array}{l}\text { Remained buoyant up to } 07 \mathrm{hr} \text {. Formulation acquired the shape of } \\
\text { irregular gel matrix. Drug release was retarded up to } 4 \mathrm{hr} \text { and release } \\
\text { pattern was found to be regular and system doesn't hold the drug for } \\
\text { longer period of time. After } 05 \text { hours irregular gel matrix ruptures. }\end{array}$ \\
\hline D6 & Nil & Buoyant for 07 hours & $68.45 \pm 1.27$ & $\begin{array}{l}\text { Remained buoyant up to } 07 \mathrm{hr} \text {. Formulation acquired the shape of regular } \\
\text { gel matrix. System does not hold the MS for longer period of time. }\end{array}$ \\
\hline D7 & Nil & Buoyant for 08 hours & $97.89 \pm 1.35$ & $\begin{array}{l}\text { Remained buoyant up to } 08 \mathrm{hr} \text {. Formulation acquired the shape of } \\
\text { cylindrical gel matrix. Drug release was retarded up to } 07 \mathrm{hr} \text {. Drug release } \\
\text { was retarded and release pattern was found to be regular. }\end{array}$ \\
\hline D8 & Nil & Buoyant for 08 hours & $95.56 \pm 1.61$ & $\begin{array}{l}\text { Remained buoyant up to } 08 \mathrm{hr} \text {. Formulation acquired the shape of } \\
\text { cylindrical gel matrix. Drug release was retarded up to } 08 \mathrm{hr} \text { and release } \\
\text { pattern was found to be regular. }\end{array}$ \\
\hline D9 & Nil & Buoyant for 09 hours & $98.89 \pm 1.01$ & $\begin{array}{l}\text { Remained buoyant up to } 09 \mathrm{hr} \text {. Formulation acquired the shape of } \\
\text { cylindrical gel matrix. Drug release was retarded up to } 09 \mathrm{hr} \text { and release } \\
\text { pattern was found to be regular. }\end{array}$ \\
\hline
\end{tabular}

*All determinations were carried out in triplicate, mean $\pm \mathrm{SD}(\mathrm{n}=3)$

\section{Drug Release Studies}

The dissolution profile of the MS loaded formulations filled in hard gelatin colorless capsule shell size 1, was performed under experimental conditions ( $\mathrm{pH} ; 0.1 \mathrm{M} \mathrm{HCl}(\mathrm{pH} 1.2)$, USP apparatus type II, temperature; $37 \pm 0.5{ }^{\circ} \mathrm{C}, \mathrm{rpm} ; 50$ ) as shown in figure 8 and 9. In the present study, we have chosen the CPR, Chitosan, and HPMC because of its ability to release the loaded drug slowly in the stomach and they are biodegradable polymers. None of the work reported in the history of drug delivery technology using CPR as gastroretentive technique. Chitosan has received attention due to its excellent biocompatibility, biodegradability, and nontoxicity. Chitosan fulfills all the polymeric attributes that are pertinent to the high level of retention of applied and targeted sites via mucoadhesive bonds. The mucoadhesive property of Chitosan is due to an electrostatic interaction of the protonated amino group in Chitosan with negatively charged silicic acid residues in mucin (the glycoprotein that composes the mucus). This interaction takes place very near to the mucosal surface and thus possesses potential to confer significant gastroretention to the hydrogel. Additionally, the hydroxyl and amino groups may interact with mucus via hydrogen bonding. Along with CPR, auxiliary polymers, HPMC and HMWCH used alone and in combination both. When auxiliary polymers are used they are expected to delay the release of MS from the monolithic system by counteracting the rapid erosion process and maintaining the developed hydrogel structure. Formulation D1 shows the $68.89 \%$ release of MS in the first three hours this is due to alone CPR is being hydrophilic polymer when it comes in contact with dissolution media it forms an hydrogel structure due to entropy favored process number of ions in hydrogel structure increases more and more osmotic and electrostatic forces created in the hydrogel structure. Being MS highly hydrophilic in nature, this reduces the aqueous gel layer due to high diffusion force and leads to erosion of a monolithic system. Due to this hydrogel lost its integrity and leading to burst release. In the formulation, D2 and D3 are combined $\mathrm{CPR}$ with $\mathrm{CH}$ and HPMC retardation time with MC increases in 06 and 08 hours and showing \% drug release 97.89 and 94.45 respectively. This is attributed due to these polymers helps in interacting with CPR to form hydrogel type structure which helps in sustaining the MS for the longer period of time and also prevents the dilution of hydrogel structure.

Formulation D4 shows the significant $(p<0.01$, D2 and D3) retardation when the equal proportion of $\mathrm{HMWCH}$ and HPMC was used only $35.67 \%$ MS release was found in the first three hours of study. But when alone HMWCH and HPMC used with MS in formulations D5 and D6, after 04 hours and 03 hours, respectively hydrogel structure disrupted due to the development of osmotic and electrostatic forces. In formulation D7, D8 and D9 on increasing the concentration of MS the release profile significantly increased and also the retardation time (1-2 hours) as compared to formulations D1-D6. This type of behavior attributed due to the in increasing the concentration of MS leads to high a degree of ordering and crystal-like properties and have quite a compact structures development after exposure to dissolution medium. In this, there is a relatively quick gel formation due to association/dissociation/binding of ions with the polymer hydrogel structures (figure 10). 


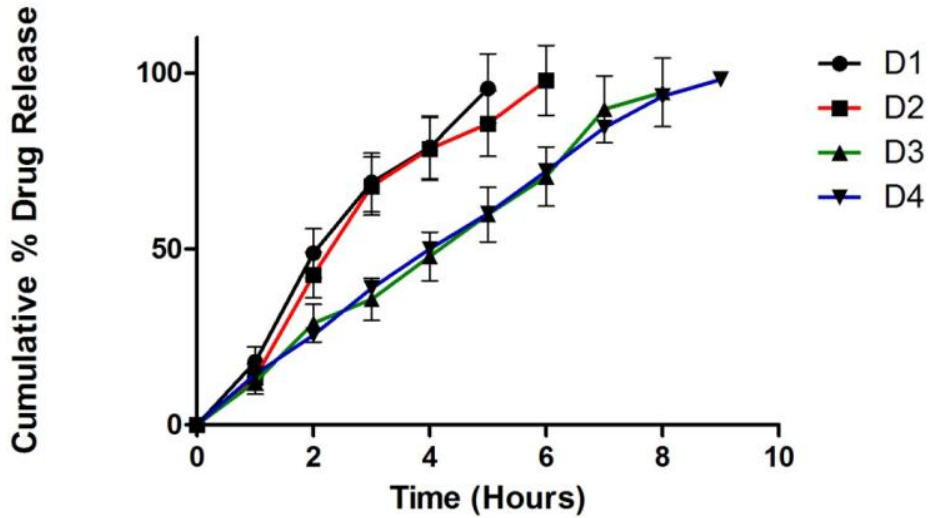

Fig 8: Cumulative \% Drug Release of formulations D1 - D4 in $0.1 \mathrm{M} \mathrm{HCl}(\mathrm{pH} 1.2)(\mathrm{n}=3$, mean \pm S.D).

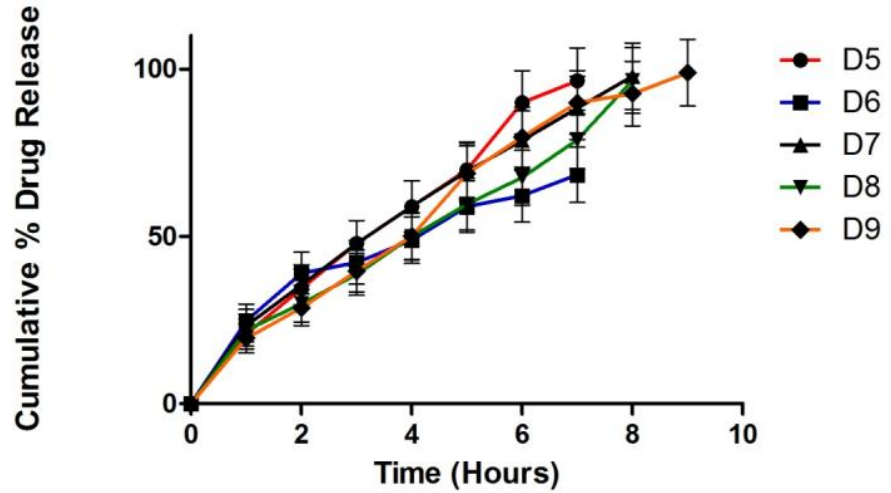

Fig. 9: Cumulative \% Drug Release of formulations D5 - D9 in $0.1 \mathrm{M} \mathrm{HCl}(\mathrm{pH} 1.2)(\mathrm{n}=3$, mean \pm S.D).

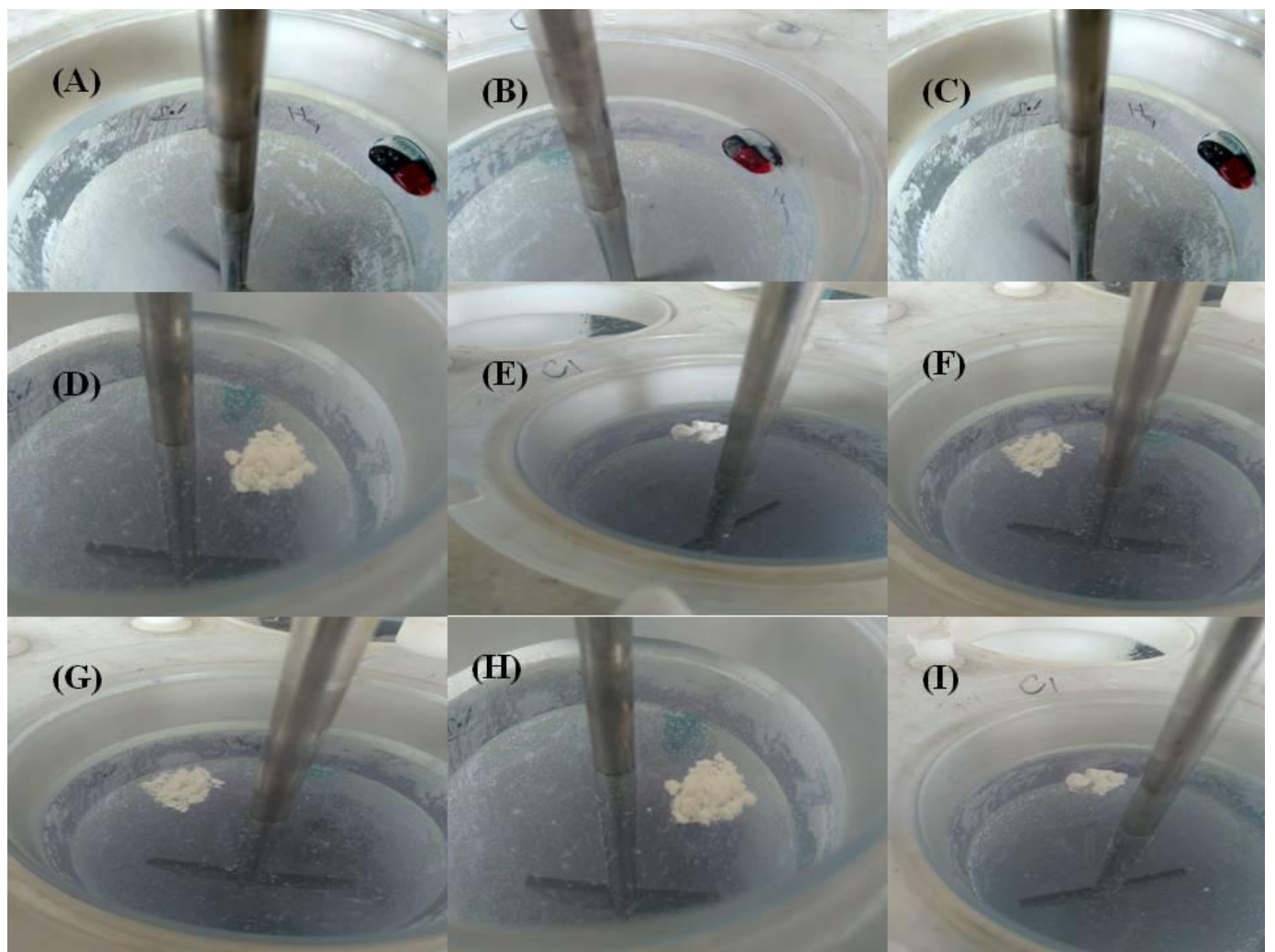

Fig. 10: Representing changes in the structure of HBS capsule system bearing MS after coming in contact with dissolution medium in $0.1 \mathrm{M}$ HCl and remained buoyant for 09 hour; formulation D4 (A) after 15 minutes (B) after 30 minutes (C) after 45 minutes (D) after 01 hour (E) after 03 hour (F) after 05 hour (G) after 07 hour (H) after 08 hour (I) after 09 hour of study without sinking in the dissolution media 
Table 5: Drug delivery kinetic and AIC value determination, determined for amount of drug which releases up to $60 \%(\mathrm{t} 60 \%)$.

\begin{tabular}{|c|c|c|c|c|c|c|c|c|c|}
\hline \multirow[t]{2}{*}{ Code } & \multicolumn{4}{|c|}{$\mathbf{r}^{2}$} & \multirow[b]{2}{*}{ n -Value } & \multicolumn{3}{|c|}{ AIC Value } & \multirow[b]{2}{*}{ Comments } \\
\hline & $\begin{array}{c}\text { Zero } \\
\text { Order }\end{array}$ & $\begin{array}{c}\text { First } \\
\text { Order }\end{array}$ & $\begin{array}{c}\text { Higuchi } \\
\text { model }\end{array}$ & $\begin{array}{c}\text { Korsmeyer- } \\
\text { Peppas }\end{array}$ & & $\begin{array}{c}\text { Zero } \\
\text { Order }\end{array}$ & $\begin{array}{c}\text { First } \\
\text { Order }\end{array}$ & $\begin{array}{c}\text { Higuchi } \\
\text { model }\end{array}$ & \\
\hline D1 & 0.9966 & 0.7104 & 0.9071 & 0.9430 & 0.45 & 41.76 & 53.23 & 45.90 & Zero order model and Fickian diffusion \\
\hline D2 & 0.9967 & 0.8768 & 0.7749 & 0.9530 & 0.40 & 39.56 & 60.12 & 69.45 & Zero order model and Fickian diffusion \\
\hline D3 & 0.9548 & 0.8760 & 0.8096 & 0.7886 & 0.44 & 56.32 & 88.12 & 61.51 & Zero order model and Fickian diffusion \\
\hline D4 & 0.9987 & 0.9670 & 0.8689 & 0.9731 & 0.43 & 58.89 & 97.65 & 65.98 & Zero order model and Fickian diffusion \\
\hline D5 & 0.9893 & 0.9751 & 0.9740 & 0.9523 & 0.42 & 43.56 & 64.12 & 89.87 & Zero order model and Fickian diffusion \\
\hline D6 & 0.9875 & 0.8604 & 0.7933 & 0.8974 & 0.43 & 58.89 & 96.78 & 89.90 & Zero order model and Fickian diffusion \\
\hline D7 & 0.9787 & 0.8764 & 0.8692 & 0.9764 & 0.45 & 44.43 & 87.78 & 49.67 & Zero order model and Fickian diffusion \\
\hline D8 & 0.9985 & 0.9127 & 0.8768 & 0.9122 & 0.44 & 52.98 & 88.23 & 66.01 & Zero order model and Fickian diffusion \\
\hline D9 & 0.9854 & 0.8967 & 0.9117 & 0.9014 & 0.43 & 65.98 & 82.23 & 56.56 & Zero order model and Fickian diffusion \\
\hline
\end{tabular}

\section{Drug Delivery kinetics and Akaike Information Criterion (AIC) value determination}

Drug release rate depends on the water penetration rate, swelling properties of the polymer, diffusion of drug through the matrixes before and after erosion when it gets in contact with the dissolution media. From the data generated from release kinetics formulations D1-D9 zero order kinetics which is shown by its $\mathrm{r}^{2}$ value. Zero-order kinetics refers the nearly uniform drug release rate, which is independent of its concentration of the drug; this type of system also shows minimum side effects. Zero-order kinetics $r^{2}$ value ranges from 0.9548 to 0.9987 and $n$ value ranges from 0.40 to 0.45 . Formulation D1- D9 follows the Fickian model. It means that the drug release from the monolithic barrier is controlled by drug diffusion through the gel barrier. When these formulations come in touch with the dissolution medium due to hydration it causes swelling which leads the development of façade viz: swelling façade, diffusion and erosion façade and all these facades are the governing parameters for the apparent motion of macromolecules from the matrix. Fickian diffusion release occurs by molecular diffusion of the drug due to a chemical potential gradient.

In addition to drug release kinetics, Akaike Information Criterion (AIC) was also determined and it is a measurement of goodness of fit. When compared with several models of data, the model related with the smallest AIC is considered as best fit model. AIC values determination reconfirms the formulations D1D9 follows zero order kinetics (table 5).

\section{CONCLUSION}

The current experimental study was conducted to get insight into the suitability of CPR, HMWCH and HPMC K15 as a carrier for the single unit HBS capsule for stomach specific drug delivery for MS. HBS capsule formulations based on CPR shows excellent buoyancy imparting agent as well as drug retarding rate also significantly increases when used in combination with other auxiliary polymers. Since, CPR has been new in the field of drug delivery technology and also as a polymer for achieving gastroretention, its low density attracted us to use as an agent which promotes the buoyancy. HBS capsules based on CPR with different grades of HPMC K15 and HMWCH as carrier reflects excellent in vitro buoyancy and were found capable of sustaining the MS release in the upper part of the GI tract. Considering the experimental results of the current experimental investigation, it can be concluded that CPR alone and in combination with HPMC $\mathrm{K} 15$ and $\mathrm{HMWCH}$ can be used as a potential carrier material for the development of single-unit HBS system for stomach specific sustained release of hydrophilic drugs with absorption window in the upper GIT. However, CPR needs an exploration in future for drug delivery technology in different $\mathrm{pH}$, different organ/tissue target, with combination with different polymers and alone itself.

\section{CONFLICT OF INTEREST}

None

\section{ACKNOWLEDGEMENT}

This research work supported by Sardar Bhagwan Singh PG Institute of Biomedical Sciences and Research, Dehradun, India. Authors are thankful to Indian Institute of Technology; IIT, Roorkee, India for characterization of samples. This paper is based, in part, on the work done for a Ph.D. degree of IFTM University, Moradabad, India by one of the author.

Conflict of Interests: There are no conflicts of interest.

\section{REFERENCES}

Bernkop-Schnürch A, Dünnhaupt S. Chitosan-based drug delivery systems. European Journal of Pharmaceutics and $\begin{array}{llll}\text { Biopharmaceutics, } & \text { 2012; } & 81(3): & 463-469 .\end{array}$ doi.org/10.1016/j.ejpb.2012.04.007

Blomqvist I, Westergren G, Sandberg A, Jonsson UE, Lundborg P. Pharmacokinetics and pharmacodynamics of controlled-release metoprolol: a comparison with atenolol. European Journal of Clinical Pharmacology, 1988; 33(1): 519-524.

Boldhane S, Kuchekar B. Development and optimization of metoprolol succinate gastroretentive drug delivery system. Acta pharmaceutica, 2010; 60(4): 415-425.

Garg R, Gupta GD. Progress in controlled gastroretentive delivery systems. Tropical Journal of Pharmaceutical Research, 2008; 7(3): 1055-1066. DOI: dx.doi.org/10.314/tjpr.v7i3.14691

Gupta NV, Shivakumar HG. Investigation of swelling behavior and mechanical properties of a $\mathrm{pH}$-sensitive superporous hydrogel composite. Iranian journal of pharmaceutical research, 2012; 11(2): 481489. PMCID: PMC 3832170

Hanafi M, Amin S, Efrina D, Suwandi B. The Use of Shrimp Shell for Chitosan and Glucosamine. J. Kimia. Terapan, 2000; 10(1-2):1721. 
Huang CB, Jeng R, Sain M, Saville B, Hubbes M. Production, characterization, and mechanical properties of starch modified by Ophiostoma spp. Bioresources, 2007; 1(2): 257-269.

Huang Y, Tang J, Swanson BG, Rasco BA. Effect of calcium concentration on textural properties of high and low acyl mixed gellan gels. Carbohydrate Polymers, 2003; 54(4): 517-522.

Jobin G, Cortot A, Godbillon J, Duval M, Schoeller JP, Hirtz J, Bernier JJ. Investigation of drug absorption from the gastrointestinal tract of man. I. Metoprolol in stomach, duodenum, and jejunum, Br. J. Clin. Pharmacology, 1985; 19: 97-105.

Katime IA, Katime O, Katime D. Smart materials of this millenium: Macromolecular hydrogels. Servicio Editorial de la Universidad del Pais Vasco: Bilbao. 2004.

Kendall MJ, Maxwell SR, Sandberg A, Westergren G. Controlled release Metoprolol. Clinical pharmacokinetic and therapeutic implications. Clinical Pharmacokinetics, 1991; 21: 319-330. PMID: 1773547, DOI: 10.2165/00003088-199121050-00001

Kizil R, Irudayaraj J, Seetharaman K. Characterization of irradiated starches by using FT-Raman and FTIR spectroscopy. Journal of agricultural and food chemistry, 2002; 50(14): 3912-3918.

Lee JW, Kim SY, Kim SS, Lee YM, Lee KH, Kim SJ. Synthesis and characteristics of interpenetrating polymer network hydrogel composed of chitosan and poly (acrylic acid). Journal of Applied Polymer Science, 1999; 73: 113-120. DOI: 10.1002/(SICI)10974628(19990705)73:1<113::AIDAPP13>3.0.CO;2-D

Martinez-Ruvalcaba A, Sánchez-Díaz JC, Becerra F, CruzBarba LE, González-Álvarez A. Swelling characterization and drug delivery kinetics of polyacrylamide-co-itaconic acid/chitosan hydrogels. Express Polymer Letters, 2009; 3(1): 25-32. DOI: 10.3144/expresspolymlett.2009.5

Narendra C, Srinath MS, Babu G. Optimization of bilayer floating tablet containing Metoprolol tartrate as a model drug for gastric retention. AAPS Pharm. Sci. Tech, 2006; 7, 23-29. DOI: 10.1208/pt070234

Ravishankar H, Patil P, Samel A, Petereit HU, Lizio R, IyerChavan J. Modulated release Metoprolol Succinate formulation based on ionic interactions: in-vivo proof of concept. J. Control. Rel, 2006; 111: 6572.

Sandberg A, Blomqvist I, Jonsson UE, Lundborg P. Pharmacokinetic and pharmacodynamic properties of a new controlledrelease formulation of metoprolol: a comparison with conventional tablets. European journal of clinical pharmacology, 1988: 33; S9-S14.

Santha N, Sudha KG, Vijayakumari KP, Nayar VU, Moorthy SN. Raman and infrared spectra of starch samples of sweet potato and cassava. Journal of Chemical Sciences, 1990; 102(5): 705-12.

Sonaje K, Chuang EY, Lin KJ, Yen TC, Su FY, Tseng MT, Sung HW. Opening of epithelial tight junctions and enhancement of paracellular permeation by chitosan: microscopic, ultrastructural and computed-tomographic observations. Molecular pharmaceutics, 2012; 9(5):1271-79.
Soni S, Verma A, Ram V. Evaluation of Chitosan-Hydroxy Propyl Methyl Cellulose as a Single Unit Hydrodynamically Balanced Sustained Release Matrices for Stomach Specific Delivery of Piroxicam. MOJ Bioequivalence Availability, 2016; 1(3): 1-14. DOI: 10.15406/mojbb.2015.01.00014

Soni S, Verma N, Verma A, Pandit JK. Gelucire based floating emulsion gel beads: a potential carrier for sustained stomach specific drug delivery. FARMACIA, 2017; 65(1): 142-152.

Verma A, Bansal A, Ghosh A, Pandit, J. Low molecular mass chitosan as carrier for a hydrodynamically balanced system for sustained delivery of ciprofloxacin hydrochloride. Acta Pharmaceutica, 2012; 62(2): 237-250. DOI: doi.org/10.2478/v10007-012-0013-2

Verma A, Dubey J, Verma N, Nayak A. ChitosanHydroxypropyl Methylcellulose Matrices as Carriers for Hydrodynamically Balanced Capsules of Moxifloxacin HCl. Current drug delivery, 2017; 14(1): 83-90.

Verma A, Wahi AK, Pandit JK. Effect of crosslinking with $\mathrm{Ca}^{++}$and $\mathrm{Zn}^{++}$ in the formation of gellan gum gels. Lat Am J Pharm, 2012; 31: 815-820.

Wikstrand J, Andersson B, Kendall MJ, Stanbrook H, Klibaner M. Pharmacokinetic considerations of formulation: extended-release metoprolol succinate in the treatment of heart failure. Journal of Cardiovascular Pharmacology, 2003; 41(2): 151-157.

Wilson RH, Goodfellow BJ, Belton PS, Osborne BG, Oliver G, Russell PL. Comparison of Fourier transform mid infrared spectroscopy and near infrared reflectance spectroscopy with differential scanning calorimetry for the study of the staling of bread. Journal of the Science of Food and Agriculture, 1991; 54(3): 471-83.

Zhang JP, Li A, Wang AQ. Study on superabsorbent composite. V. Synthesis, swelling behaviors and application of poly (acrylic acid-co-acrylamide)/sodium humate/attapulgite superabsorbent composite. Polymers for advanced technologies, 2005; 16(11-12): 813-820

\section{How to cite this article:}

Soni S, Ram V, Verma A. Crushed Puffed Rice-HPMC-Chitosan based Single-Unit Hydro-dynamically Balanced System for the Sustained Stomach Specific Delivery of Metoprolol Succinate. J App Pharm Sci, 2017; 7 (12): 047-057. 